\title{
Dampak dari Risiko Fisik, Kepuasan, Waktu dan Keuangan terhadap Kunjungan Kembali ke Kota Batam
}

\author{
Hanny $^{1}$, Lia Andriani ${ }^{2}$ \\ ${ }^{1}$ Universitas Internasional Batam, Indonesia. hanny.lec@uib.ac.id \\ ${ }^{2}$ Universitas Internasional Batam, Indonesia.1641153.lia@uib.edu
}

\begin{abstract}
ABSTRAK
Penelitian yang telah dilakukan memiliki tujuan untuk mengetahui pengaruh dari risiko fisik, kepuasan, waktu dan keuangan terhadap niat berkunjungan kembali. Sampel yang diambil untuk penelitian ini berjumlah 300 sampel yang pernah mengunjungi Kota Batam. Respondennya berupa wisatawan lokal serta pengolahan data menggunakan sistem SPSS. Hasil pengujian dalam penelitian ini adalah risiko waktu dan keuangan bersignifikan terhadap berkunjungan kembali sedangkan risiko fisik \& kepuasan tidak signifikan terhadap berkunjung kembali. Penelitian ini memiliki keterbatasan yaitu variabel dalam penelitian masih sedikit. Beberapa hasil data yang diolah belum maksimal sehingga masih harus diperbaiki. Harapannya bahwa penelitian selanjutnya dapat menggunakan ini sebagai dasar referensi untuk penelitian serta menyempurnakan penelitian ini agar dapat berguna bagi masyarakat. Peneliti juga berharap untuk menambahkan ataupun menggantikan variabel yang digunakan dalam penelitian selanjutnya agar hasil lebih maksimal
\end{abstract}

Kata Kunci: Risiko Fisik, Kepuasan, Waktu, Keuangan, Kunjungan Kembali.

ABSTRACT

The research that has been done has the objective of knowing the effect of physical risk, satisfaction, time, and finance on the intention to visit again. The sample taken for this study amounted to 300 samples who had seen Batam City. Respondents are local tourists, and data processing uses the SPSS system. This study's test results were time, and financial risks were significant for return visits, while physical risks and satisfaction were not significant for return visits. This study has limitations, namely, the variables in the study are still few. Some of the processed data results have not been maximized, so they still need to be improved. It is hoped that further research can use this as a reference basis for research and refine this research so that it can be of use to society. Researchers also hope to add or replace the variables used in further research for maximum results.

Keywords: Physical Risk, Satisfaction, Time, Financial, Revisit Intention.

Diterima: 25 Jan 2021, Direvisi: 1 Feb 2021, Dipublikasi: 15 Feb 2021 


\section{PENDAHULUAN}

Berdasarkan penelitian Irawan (2010), dikatakan bahwa kata pariwisata berarti pari yang memiliki arti berkeliling \& berputar-putar dan kata wisata bermaksud berpergian dan perjalanan dalam bahasa Sansekerta. Dengan demikian, kata pariwisata berarti suatu perjalanan yang dilakukan secara berkeliling maupun berputar dari sebuah lokasi ke lokasi lain. Pariwisata adalah sebuah sektor yang memiliki nilai signifikan secara ekonomi bagi suatu negara. Sektor pariwisata ini dapat membuka lapangan kerja dan menjadi sumber dari penghasilan ekonomi negara tersebut. Bagi Indonesia, sektor ini merupakan sumber devisa terbesar. Produk-produk di bidang pariwisata ini mempunyai sifat atau karakter khusus yaitu tangible product seperti accommodation, transportation, meeting room, restaurant, minuman dan lain-lain. Sedangkan intangible product adalah produk tidak nyata yang juga ada seperti kualitas dari pelayanan, senyum sapa, kesopanan, keramahan, dan kepuasan dari seorang turis.

Dapat dilihat dari tabel dibawah ini bahwa wisatawan yang melakukan kunjungan pada tahun 2018 menurut data BPS dengan total 1.883.244 jiwa. Menurut data tersebut dapat dikatakan wisatawan tertarik untuk melakukan perjalanan wisata. Batam merupakan kota wisata yang memiliki lokasi yang sangat strategis bagi wisatawan yang mengunjunginya. Selain dari itu, Kota Batam mempunyai banyak tujuan destinasi wisata yang bisa dinikmati wisatawan. Destinasi wisata berupa tempat wisata alam yaitu pantai, tempat wisata kuliner seperti makanan khas Indonesia, seafood, Indian cuisine, Japanese cuisine, dan makanan unik lainnya yang dapat dinikmati, wisata adat \& budaya seperti rumah miniatur serta beberapa festival perayaan, wisata religi seperti Masjid Raya, Masjid Cheng Ho, Vihara Duta Maitreya dan lain sebagainya, wisata sejarah seperti Kampung Vietnam dan wisata belanja seperti Nagoya Hill Shopping Senter, BCS, Grand Batam, Mega Mall serta pasar traditional yang cukup terkenal bagi wisatawan lokal baik wisatawan Indonesia maupun wisatawan asing.

Untuk mengetahui apakah wisatawan akan berkunjung kembali lagi serta beberapa faktor dan hal-hal penting yang dapat mempengaruhi seperti physical risk (fisik), satisfaction risk (kepuasan), time risk (waktu), financial risk (keuangan) terutama bagi wisatawan Indonesia untuk kembali berkunjung ke kota tersebut maka dilakukan penelitian ini. Faktor penting terdapat pada penelitian diambil dari beberapa jurnal yang merupakan penelitian terdahulu sebagai dasar ataupun referensi bagi peneliti. Faktor risiko fisik adalah kemungkinan bagi wisatawan untuk mengalami kecelakaan secara fisik selama masa berlibur, risiko kepuasan adalah kemungkinan bagi wisatawan untuk tidak memuaskan, risiko waktu adalah kemungkinan berlibur membuang waktu secara sia-sia, serta risiko keuangan adalah kemungkinan liburan ini tidak akan memberikan nilai untuk uang yang telah dihabiskan wisatawan. Penelitian ini tidaklah sempurna namun bisa menjadi gambaran bagi peneliti lainnya untuk menggunakan penelitian ini.

\begin{tabular}{lc} 
Tabel 1. Jumlah Wisatawan ke Kota Batam \\
\hline Bulan & $\begin{array}{c}\text { Banyak Kunjungan (Jiwa) } \\
\text { Kunjungan Wisatawan Masuk } \\
\text { ke Batam 2018 }\end{array}$ \\
\hline Januari & 115551 \\
Februari & 155670 \\
Maret & 175194 \\
April & 144104 \\
Mei & 142157 \\
Juni & 167398 \\
Juli & 144235 \\
Agustus & 159218 \\
September & 153944 \\
Oktober & 141337 \\
November & 155283 \\
Desember & 233153 \\
\hline
\end{tabular}

Sumber: Data Primer diolah (2020)

Permasalahan penelitian yang ada di latar belakang penelitian yang berupa analisis risiko fisik, risiko kepuasan, risiko waktu dan risiko keuangan mempengaruhi wisatawan untuk berkunjung kembali ke Kota Batam. Ada beberapa tujuan pada penelitian ini yaitu untuk mengetahui pengaruh penting dari risiko fisik, risiko kepuasan, risiko waktu dan risiko keuangan.

\section{KAJIAN PUSTAKA \\ Model-Model Penelitian Terdahulu}

Dalam delapan tahun terakhir, penelitian mengenai revisit intention di suatu destinasi masih diteliti banyak peneliti oleh masyarakat. Hal ini ditunjukkan mencapai 35 jurnal bahkan lebih melalui pencarian Google Scholar dengan kata kunci revisit intention. Berdasarkan 35 jurnal, ditahun 2015 topik revisit intention mencapai angka tertinggi dibandingkan tahun beberapa tahun sebelum dan sesudahnya yaitu tahun 2009 sebanyak 2 kali, tahun 2010, 2011 dan 2012 masing-masing sebanyak 1 kali, di tahun 2013 sebanyak 4 kali, tahun 2016 sebanyak 8 kali dan 2017 sebanyak 4 kali. 
Topik ini diteliti di negara berkembang sebanyak 17 jurnal yang berasal dari negara yang berbeda- beda. Pada kategori negara berkembang, negara dengan jurnal terbanyak di teliti adalah negara Malaysia. Terdapat sebanyak 7 jurnal dengan dengan kategori negara Malaysia yaitu Abdullahet al.(2016), Goh (2015), Hashemiet al, 2015, Aziz et al. 2012, Ali (2015), Chew \& Jahari (2014) dan Hasan, Ismail, \& Islam (2017). Dari negara Indonesia terdapat sebanyak 5 jurnal (Herstanti, Suhud, \& Ferry WIBOWO, 2014; Hussein, 2016; Pantouw \& Pangemanan, 2014; Pratminingsih, 2014; Sobari, Usman, \& Wathani, 2017). Berasal dari negara Myanmar terdapat 1 jurnal (Chen, Htaik, Hiele, \& Chen, 2017), berasal dari Serbia sebanyak 1 jurnal (Marinkovic, Senic, Ivkov, Dimitrovski, \& Bjelic, 2014), dari Iran terdapat 1 jurnal (Ranjbarian \& Pool, 2015), dari Thailand terdapat 1 jurnal (Pattarakitham, 2015) dan dari Vietnam terdapat 1 jurnal (Thi Minh Pham, Nga Do, \& Minh Phung, 2016).

Dikategori negara maju terdapat 18 jurnal dengan negara yang berasal dari beberapa negara yang berbeda. Negara China merupakan negara dengan kategori negara maju terbanyak yang diteliti yaitu terdapat 4 jurnal (Loi, So, Lo, \& Fong, 2017; Shen, 2013; Song, Kim, \& Yim, 2017; Zhou, 2011). Berasal dari Denmark sebanyak 1 jurnal (Barnes, Mattsson, \& Sørensen, 2016), berasal dari Hongkong 1 jurnal (Huang \& Hsu, 2009), dari Italy 1 jurnal (Jung, Ineson, Kim, \& Yap, 2015), berasal dari Taiwan 3 jurnal (Hung, Lee, \& Huang, 2016; Lin, 2013; Liu \& Lee, 2016) berasal dari Korea Selatan sebanyak 2 jurnal (Kim, Song, Lee, \& Lee, 2017; Lee \& Kang, 2015), dari Turkey sebanyak 3 jurnal (Artuğer, 2015; Çetinsöz \& Ege, 2013; Tosun, Dedeoğlu, \& Fyall, 2015), dari United Arab Emirates sebanyak 1 jurnal (Julaimi \& Talib, 2016) dan dari USA sebanyak 2 jurnal yaitu (Han, Back, \& Barrett, 2009; Li, Cai, Lehto, \& Huang, 2010).

Industri yang ditelilti untuk topik ini lebih kearah industri pariwisata dengan jumlah journal sebanyak 18 journal yaitu (Artuğer, 2015; Barnes et al., 2016; Çetinsöz \& Ege, 2013; Chen et al., 2017; E. Y. T. Chew \& Jahari, 2014; Hasan et al., 2017; Hashemi et al., 2015; Herstanti et al., 2014; Huang \& Hsu, 2009; Hung et al., 2016; Julaimi \& Talib, 2016; Jung et al., 2015; Li et al., 2010; Pattarakitham, 2015; Pratminingsih, 2014; Ranjbarian \& Pool, 2015; Shen, 2013; Tosun et al., 2015), industri Air Transport (Liu \& Lee, 2016), industri Event (Hussein, 2016), industri Gaming (Kim et al., 2017), industri Hotspring
(Lin, 2013), industri Golf tourism (Song et al., 2017), industri Perhotelan sebanyak 4 jurnal (Abdullah et al., 2016; Goh, 2015; Sobari et al., 2017; Zhou, 2011), industri Resor (Ali, 2015; Pantouw \& Pangemanan, 2014), industri restoran sebanyak 3 jurnal (Han et al., 2009; Marinkovic et al., 2014; Thi Minh Pham et al., 2016), industri Theme Park (Aziz et al., 2012), industri Sport (Lee \& Kang, 2015), dan industri Tourism Transportation (Loi et al., 2017).

Ada beberapa kategori responden yaitu local tourist, foreign tourist, visitor/guest/customer, employee. Terdapat sebanyak 26 jurnal dengan kategori visitor/guest/customer, employee. sebanyak 6 jurnal merupakan turis lokal, 3 jurnal turis asing dan 1 jurnal respondennya merupakan karyawan. Berdasarkan itu bisa disimpulkan bahwa masih banyak peneliti yang tertarik dalam topik ini dan akan terus menelitinya.

\section{Hubungan antar Variabel \\ Pengaruh Risiko Fisik terhadap Keinginan untuk Berkunjung Kembali \\ Seperti yang dilakukan dengan turis} Malaysia yang pernah mengunjungi Jepang sebelumnya dan menyimpulkan bahwa hanya risiko fisik yang dirasakan yang akan memengaruhi mereka niat untuk mengunjungi kembali. Studi lebih lanjut fokus pada efek dari sikap wisatawan yang berulang terhadap risiko yang dirasakan. Dalam sebuah studi oleh (Sönmez \& Graefe, 1998b) 10 tipe risiko ditentukan sebagai berikut: peralatan, keuangan, kesehatan, fisik, stabilitas politik, psikologis, kepuasan, sosial, terorisme, dan waktu. Mereka menyelidiki apakah tipe risiko ini mempengaruhi masa depan rencana perjalanan untuk berbagai tujuan, dengan fokus utama pada kerusuhan politik dan terorisme. Ditemukan bahwa wisatawan menghindari rencana kunjungan kembali ke Asia dan Amerika Selatan karena alasan politik kerusuhan.

Hal yang sama berlaku untuk Timur Tengah dan Afrika karena tingginya risiko terorisme. Riset lainnya menemukan bahwa turis kembali lagi ke daerah yang dilanda tsunami karena masih berhubungan dengan urusan pribadi dengan daerah tersebut. Penelitian serupa menunjukkan bahwa ketika kontak dengan dan pengalaman tujuan meningkat, persepsi risiko tingkatannya menurun, mengarah pada sikap yang lebih positif terhadap pariwisata internasional (Rittichainuwat \& Chakraborty, 2009; So"nmez \& Graefe, 1998). 


\section{Pengaruh Risiko Kepuasan terhadap Keinginan untuk Berkunjung Kembali}

Salah satu studi pertama tentang persepsi risiko dalam literatur pariwisata dilakukan oleh Roehl dan Fesenmaier (1992). Studi yang dilakukan oleh penulis menunjukkan risiko yang dirasakan oleh wisatawan selama mereka liburan. Penulis menentukan tujuh jenis risiko yaitu risiko peralatan, keuangan, fisik, sosial, kepuasan dan waktu (Fuchs \& Reichel, 2006). Sönmez dan Graefe (1998) menentukan empat jenis risiko terkait pariwisata. Risiko-risiko ini adalah risiko keuangan, psikologis, kepuasan dan waktu yang terkait. Sebagai hasil dari analisis faktor, faktor diklasifikasikan berdasarkan nama aslinya. Dalam literatur pariwisata, meskipun faktor risiko (fisik, kinerja, kepuasan, politik, keuangan, waktu, dan sosial- psikologis) yang digunakan oleh Fuchs dan Reichel (2004, 2006), Roehl dan Fesenmaier (1992), dan So"nmez dan Graefe (1998a, 1998b) adalah ditentukan, ditemukan bahwa variabel risiko keuangan berada di bawah risiko kepuasan dimensi karena responden mempersepsikan faktor risiko keuangan bersama dengan risiko kepuasan. Selanjutnya, meskipun responden merasakan risiko politik variabel agak tidak signifikan, dimensi risiko politik tidak dimasukkan karena beban faktor rendah dan menyimpang signifikansi unsur-unsur faktor.

\section{Pengaruh Risiko Waktu terhadap Keinginan untuk Berkunjung Kembali}

Cetinsoz dan Ege (2013) melakukan penelitian untuk mengetahui bagaimana tingkat risiko yang dirasakan oleh para wisatawan yang mengunjungi Alanya selama mereka tinggal mempengaruhi niat mengunjungi kembali mereka dan menemukan risiko fisik, kepuasan dan waktu secara negatif pengaruh pada keingian untuk berkunjung kembali. Quintal et al. (2010) juga membuat klaim serupa dalam penelitian sebelumnya bahwa risiko yang dirasakan mempengaruhi sikap wisatawan yang negatif terhadap kunjungan ke Australia, Korea Selatan dan Jepang.Sebuah studi oleh Roselius (1971) menunjukkan bahwa konsumen merasakan empat risiko yang berbeda yaitu waktu, bahaya, ego, dan uang (Lacey et al, 2009).

Jacoby dan Kaplan (1972) menunjukkan bahwa yang dirasakan oleh wisatawan mengenai risiko terdapat pada 5 jenis risiko yaitu psikologis, sosial, finansial, fisik dairisiko kinerja. Mitchell (1992) menetapkan bahwa terdapat 6 dimensi atu jenis yaitu social, financial, physical, performance, time and psychological risk. Sebuah penelitian yang dilakukan oleh Stone dan Gronhaug (1993) mengungkapkan enam jenis risiko. Ini adalah risiko keuangan, kinerja, fisik, psikologis, sosial dan waktu (Lin \& Chen, 2009). Salah satu studi pertama tentang persepsi risiko dalam literatur pariwisata dilakukan oleh Roehl dan Fesenmaier (1992). Studi yang dilakukan oleh penulis menunjukkan risiko yang dirasakan oleh wisatawan selama mereka liburan. Penulis menentukan tujuh jenis risiko yaitu risiko keuangan, peralatan, fisik, sosial, kepuasan dan waktu. (Fuchs \& Reichel, 2006). Sönmez dan Graefe (1998) menentukan empat jenis risiko terkait pariwisata. Risiko-risiko ini adalah risiko keuangan, psikologis, kepuasan dan waktu yang terkait.

\section{Pengaruh Risiko Keuangan terhadap Keinginan untuk Berkunjung Kembali}

Faktor yang paling signifikan dengan niat wisatawan yang mengunjungi Marmaris untuk mengunjungi kembali (revisit intention) adalah risiko keuangan (financial risk). Tujuannya adalah untuk menemukan beberapa dampak maupun risiko- risiko yang dapat mempengaruhi wisatawan terhadap keinginan mereka untuk melakukan kunjungan kembali dan sebagai hasil dari analisis faktor ditentukan bahwa risiko yang dirasakan oleh wisatawan memiliki lima dimensi. Risiko-risiko ini adalah risiko sosio-psikologis, risiko waktu, risiko keuangan, dan risiko kinerja. Fuchs dan Reichel (2006) melakukan penelitian di Israel dengan 760 wisatawan dan menentukan bahwa manusia risiko sumber daya, risiko keuangan, risiko kualitas layanan, risiko sosialpsikologis, bencana alam dan lalu lintas risiko kecelakaan, keamanan pangan, dan kondisi cuaca dianggap sebagai risiko oleh para wisatawan.

Schroeder et al (2013) melakukan penelitian dengan 4000 warga AS untuk menentukan risiko yang dirasakan selama Olimpiade musim panas 2012 di London. Dari hasil penelitian, risiko yang dirasakan oleh warga Amerika di London adalah bencana alam, virus SARS, keamanan pangan, krisis keuangan, masalah infrastruktur, kondisi cuaca buruk, masalah politik dan aksi teror. Studi pada (Artuğer, 2015) mengungkapkan bahwa niat wisatawan yang mengunjungi Marmaris untuk kembali dipengaruhi oleh sosiopsikologis risiko, risiko waktu, risiko fisik, risiko keuangan, dan dimensi risiko kinerja yang mereka pahami selama mereka tinggal. Juga ditentukan bahwa faktor risiko yang paling signifikan dengan dampak pada niat wisatawan yang berkunjung kembali adalah 
risiko keuangan, sedangkan faktor yang paling tidak mengesankan adalah risiko sosialpsikologis.

\section{Model Penelitian dan Perumusan Hipotesis}

Pada model penelitian yang digambarkan dibawah, maka dapat dirumuskan hipotesis yaitu:

H1: Risiko fisik mempengaruhi berkunjung kembali.

H2: Risiko kepuasan mempengaruhi berkunjung kembali.

H3: Risiko waktu terhadap berkunjung kembali.

H4: Risiko waktu terhadap berkunjung kembali.

\section{METODOLOGI PENELITIAN \\ Variabel dan Pengukuran}

Metode yang digunakan pada penelitian ini adalah kuantitatif yaitu sebuah teknik penelitian yang difungsikan untuk meneliti sebuah populasi ataupun sampel khusus yang berfondasi pada filsafat positivisme, kemudian agar dapat mengumpulkan data menggunakan alat dan instrumen penelitian, serta analisa informasi dan data yang memiliki sifat kuantitatif ataupun sebuah statistic. Variabel yang dimaksud adalah keinginan untuk mengunjungi kembali (revisit intention) sebagai variabel independen, variabel risiko fisik (physical risk), risiko kepuasan (satisfaction risk), risiko waktu (time risk) serta risiko keuangan (financial risk) sebagai variabel dependen. Penelitian yang diteliti ini digunakan sebagai landasan penelitian dengan maksud tujuan untuk menguraikan teori yang dibuat peneliti serta mendeskripsikan fenomena alam maupun fenomena sosial yang ada.

\section{Objek Penelitian dan Teknik Analisis}

Research object atau yang disebut dengan objek penelitian menurut Supranto (2000) berarti sasaran yang akan diteliti pada penelitian tersebut baik berupa barang, orang ataupun sebuah organisasi. Sedangkan menurut seorang ahli yaitu Sugiyono (2012) populasi penelitian adalah suatu zona yang mencakup subjek \& objek dengan mutu serta karakterisk yang sudah ditentukan pada penelitian tersebut selanjutnya ditarik hasil dan kesimpulan. Populasi yang dipakai untuk penelitian ini adalah turis atau wisatawan, sedangkan target populasinya dari penelitan ini adalah wisatawan yang telah berkunjung pada kota yang dilakukan penelitian, yaitu Kota Batam. Kota Batam memiliki populasi berjumlah 1.887.244 (Badan Pusat Statistik, 2018) sesuai dengan data ini.
Tabel 2. Jumlah Wisatawan ke Kota Batam

\begin{tabular}{lc}
\hline Bulan & $\begin{array}{c}\text { Banyak Kunjungan (Jiwa) } \\
\text { Kunjungan Wisatawan Masuk } \\
\text { ke Batam 2018 }\end{array}$ \\
\hline Januari & 115551 \\
Februari & 155670 \\
Maret & 175194 \\
April & 144104 \\
Mei & 142157 \\
Juni & 167398 \\
Juli & 144235 \\
Agustus & 159218 \\
September & 153944 \\
Oktober & 141337 \\
November & 155283 \\
Desember & 233153 \\
\hline
\end{tabular}

Sumber: Data Primer diolah (2020)

Peneliti menggunakan aplikasi IBM SPSS Statistics version 24 dalam menguji data numerikal yang didapatkan. Nilai dari data tersebut kemudian dianalisa melalui beberapa tahapan. Tahapan yang diuji yaitu ujideskriptif, uji kualitas data berdasarkan kepada uji validitas, uji reliabilitas, dan uji outlier, selanjutnya melakukan tahapan uji asumsi klasik yaitu uji normalitas, uji multikolinearitas, dan uji heteroskedastisitas, dan terakhir melakukan uji hipotesis yaitu uji F, uji t, dan uji koefisien determinasi.

\section{HASIL DAN PEMBAHASAN \\ Analisa Demografi Responden}

Peneliti melakukan membagikan kuesioner selama bulan November 2019 - Februari 2020. Dari 372 kuesioner yang telah dibagikan, peneliti menggunakan 300 responden yang dianggap layak di uji diambil dari hasil responden yang melakukan kunjungan kembali ke Kota Batam dengan tujuan berwisata.

Tabel 3. Hasil Penyebaran Kuesioner

\begin{tabular}{ll}
\hline Bulan & $\begin{array}{l}\text { Jumlah } \\
\text { Responden }\end{array}$ \\
\hline Yang telah disebarkan & 372 \\
Tidak dikembalikan & 72 \\
Tidak diisi & 0 \\
Layak diuji & 300 \\
\hline
\end{tabular}

Sumber: Data Primer diolah (2020)

Berdasarkan hasil yang diperoleh, reponden berjenis kelamin laki-laki adalah terbanyak dengan jumlah sebanyak 151 responden, sedangkan jenis kelamin perempuan sebanyak 149 responden. Dapat dilihat hanya selisih sedikit dikarenakan biasanya wistawan yang melakukan kunjungan dengan tujuan berwisata berpasangan. Peneliti dapat menyimpulkan ini dikarenakan data terbanyak responden yang diambil dari hotel. 
Klasifikasi menurut umur responden bervariasi dengan kelompok usia terbesar yaitu 21-30 tahun sebanyak $32 \%$, selanjutnya berusia 31-40 tahun sebanyak $28 \%$, selanjutnya berusia 41-50 tahun sebanyak $18 \%$, selanjutnya berusia $<20$ sebanyak $12,7 \%$ dan responden dengan usia $>50$ tahun sebanyak 9,3\%, maka dapat ditarik kesimpulannya.

Pembagian responden berdasarkan jenis pekerjaan yang dimiliki, terdapat sebanyak $20 \%$ atau 60 responden yang merupakan pelajar, $28 \%$ atau 84 responden bekerja sebagai wiraswasta, $43,3 \%$ atau 130 responden bekerja sebagai karyawan, $8,7 \%$ atau 26 responden adalah pensiunan. Data yang diambil dan digunakan dalam penelitian ini berdasarkan tujuan dari wisatawan yang datang ke Batam yaitu berwisata. Mengklasifikasi responden dari total pengeluaran pada saat ke Batam yaitu sebanyak $17,3 \%$ atau 52 responden mengeluarkan < $\mathrm{Rp} 2.000 .000$, $32,7 \%$ atau 98 responden mengeluarkan $\mathrm{Rp}$ 2.000.001-3.000.000, 34,7\% atau 104 responden mengeluarkan Rp 3.000.001 - 5.000.000, dan sebanyak $15,3 \%$ atau 46 responden mengeluarkan > Rp 5.000.001 pada saat berkunjung ke Batam.

\section{Karakteristik Variabel}

Variabel yang digunakan pada penelitian ini adalah 4 independent variable dan 1 dependent varible dengan pertanyaan secara keseluruhan adalah 23 butir menggunakan likert. Statistik deskriptif digunakan untuk mengukur mean, nilai min dan maks, dan standard deviation. Dari hasil pengolahan data menunjukkan bahwa risiko fisik memiliki nilai rata-rata 1,447 . Artinya, responden tidak mengkhawatirkan risiko-risiko yang dapat terjadi di kota tujuan seperti masalah makanan dan minuman, penyakit menular, pencurian dan perampokan, teroris dan kerusuhan politik. Terlihat dari hasil diatas standard deviation untuk risiko fisik senilai 0,52671 atau $36,458 \%$ dari ratarata maka dapat dikata memiliki variasi, menurut Santoso (2012) data dapat dikatakan memilki variasi jikai standard deviation > 33\% dari nilai mean atau rata-rata.

Nilai mean variabel risiko kepuasan adalah 1,5993. Hal ini dapat dikata bahwa responden memiliki respon negatif terhadap ketidaknyamanan pada polusi, lingkungan destinasi yang buruk, lebih mahal dibandingan dengan tempat lain, tidak nyaman dengan kebersihan makanan, nilai rupiah terlalu tinggi dan adanuya biaya tidak terduga ketika berlibur.Terlihat dari hasil diatas standard deviation untuk risiko kepuasan adalah 0,65005 ataupun $40,646 \%$ dari nilai mean maka dapat dikata cukup bervariasi.

Variabel risiko waktu mempunyai nilai rata-rata sebesar 1,4787.Berarti responden tidak merasa bahwa waktu liburan terbuang sia-sia, membuang waktu responden dan juga merasa kecewa.Terlihat dari hasil diatas standard deviation untuk risiko waktu adalah 0,58765 atau $39,741 \%$ dari nilai mean maka dapat dikata cukup bervariasi. Variabel risiko keuangan mempunyai nilai mean sebesar 1,6897, maka data diatas menunjukkan bahwa responden tidak merasa bahwa pelayanan yang diterima tidak sepadan dengan uang yang dikeluarkan, adanya biaya tambahan, lebih mahal dari kota asal, serta pengeluaran melibihi anggaran yang ditetapkan. Terlihat dari hasil diatas standard deviation untuk risiko keuangan adalah 0,79919 atau 47,298\% dari nilai mean maka dapat dikata cukup bervariasi.

\section{Uji Outlier}

Penelitian ini menguji nilai $\mathrm{z}$ ( $z$ - score) menggunakan sistem SPPS. Nilai z tidak boleh melebihi +3 ataupun kurang dari -3 , jika persyaratan tersebut dilanggar maka data yang melebihi nilai tersebut merupakan data yang menyimpang. Dari penelitian ini, diperoleh sebanyak 18 data responden yang menyimpang (terkena outlier). Data terlampir di bagian lampiran dalam laporan.

\section{Uji Validitas}

Uji ini bertujuan untuk memastikan bahwa pertanyaan yang telah disebar oleh penelili sesuai dan sah untuk digunakan dalam penelitian ini. Pertanyaan yang di katakana valid jika loading factor $>0,6$ (Hairet al, 2010).

Tabel 4. Hasil Uji Validitas

\begin{tabular}{llcl}
\hline & $\begin{array}{c}\text { Butir } \\
\text { Pertanyaan }\end{array}$ & $\begin{array}{c}\text { Hasil } \\
\text { Uji }\end{array}$ & Simpulan \\
\hline Risiko & RsF - 1 & 0,823 & Valid \\
Fisik & RsF - 2 & 0,736 & Valid \\
& RsF - 3 & 0,790 & Valid \\
& RsF - 4 & 0,646 & Valid \\
& RsF - 5 & 0,768 & Valid \\
Risiko & RsKp - 1 & 0,857 & Valid \\
Kepuasan & RsKp - 2 & 0,731 & Valid \\
& RsKp - 3 & 0,826 & Valid \\
& RsKp - 4 & 0,806 & Valid \\
& RsKp - 5 & 0,730 & Valid \\
& RsKp - 6 & 0,532 & Invalid \\
& RsKp - 7 & 0,771 & Valid \\
Risiko & RsW - 1 & 0,878 & Valid \\
Waktu & RsW - 2 & 0,736 & Valid \\
& RsW - 3 & 0,862 & Valid \\
Risiko & RsKu - 1 & 0,786 & Valid
\end{tabular}




\begin{tabular}{llcl}
\hline & $\begin{array}{c}\text { Butir } \\
\text { Pertanyaan }\end{array}$ & $\begin{array}{c}\text { Hasil } \\
\text { Uji }\end{array}$ & Simpulan \\
\hline Keuangan & RsKu - 2 & 0,828 & Valid \\
& RsKu - 3 & 0,773 & Valid \\
& RsKu - 4 & 0,854 & Valid \\
Berkunjung & BK - 1 & 0,739 & Valid \\
Kembali & BK - 2 & 0,723 & Valid \\
& BK - 3 & 0,835 & Valid \\
& BK - 4 & 0,763 & Valid \\
\hline
\end{tabular}

Sumber: Data Primer diolah (2020)

Dapat dilihat dari hasil diatas bahwa semua pertanyaan yang digunakan pada penelitian ini memiliki loading factor lebih besar dari 0,6 maka dinyatakan valid.

\section{Uji Reliabilitas}

Tujuan dari uji ini untuk menganalisa dan identifikasi keserasian responden dan jika pertanyaan tersebut konsisten \& stabil serta handal maka dapat disebutkan sebagai reliable. Variabel disebut reliable jika hasil pengujiannya memilki nilai cronbach's alpha yang lebih dari angka 0,6.

Tabel 5. Hasil Uji Reliabilitas

\begin{tabular}{lcc}
\hline \multicolumn{1}{c}{ Variabel } & $\begin{array}{c}\text { Cronbach's } \\
\text { Alpha }\end{array}$ & Kesimpulan \\
\hline Risiko Fisik & 0,806 & \\
Risiko & 0,872 & \\
Kepuasan & Reliabel \\
Risiko Waktu & 0,765 & \\
Risiko & 0,824 & \\
Keuangan & & \\
$\begin{array}{l}\text { Berkunjung } \\
\text { Kembali }\end{array}$ & 0,756 & \\
\hline
\end{tabular}

Sumber: Data Primer diolah (2020)

\section{Uji Normalitas}

Gambar dibawah ini merupakan hasil uji dari pengaruh dependent variables atau varibel bebas yaitu risiko fisik, risiko kepuasan, risiko waktu dan risiko keuangan terhadap independent variable atau variabel terikat yaitu keputusan berkunjung kembali. Dapat dilihat bahwagambar dibawahi ini agak melengkung dan sedikit menjauhi garis diagonal, kesimpulannya tidak terdistribusi secara normal.

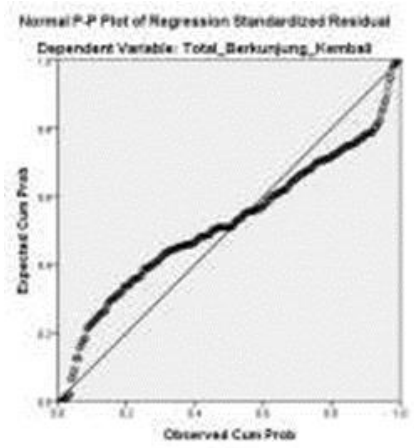

Gambar 1. Hasil Uji Normalitas Data.

\section{Uji Multikolinieritas}

Uji ini bertujuan untuk mengetahui nilai VIF. Nilai VIF harus kurang dari angka 10 untuk mengetahui pengaruhrisiko fisik, risiko kepuasan, risiko waktu dan risiko keuangan terhadap keputusan berkunjung kembali.

Tabel 6. Hasil Uji Mutikolinearitas

\begin{tabular}{|c|c|c|c|}
\hline Variabel & Tol. & VIF & Kesimpulan \\
\hline $\begin{array}{l}\text { Risiko } \\
\text { Fisik }\end{array}$ & 0,27 & 3,74 & $\begin{array}{c}\text { Tidak terjadi } \\
\text { multikolineritas }\end{array}$ \\
\hline $\begin{array}{l}\text { Risiko } \\
\text { Kepuasan }\end{array}$ & 0,22 & 4,46 & $\begin{array}{l}\text { Tidak terjadi } \\
\text { multikolineritas }\end{array}$ \\
\hline $\begin{array}{l}\text { Risiko } \\
\text { Waktu }\end{array}$ & 0,42 & 2,38 & $\begin{array}{c}\text { Tidak terjadi } \\
\text { multikolineritas }\end{array}$ \\
\hline $\begin{array}{l}\text { Risiko } \\
\text { Keuangan }\end{array}$ & 0,30 & 3,36 & $\begin{array}{c}\text { Tidak terjadi } \\
\text { multikolineritas }\end{array}$ \\
\hline
\end{tabular}

\section{Uji Heteroskedastisitas}

Untuk menguji mode regresi apakah model tersebut adanya ketidaksamaan antara variance dan residual suatu pengamatan ke lainnya. Uji ini dapat dilihat pada bintik-bintik scatterplot berkumpul di suatu titik, sehingga kesimpulan uji terjadi heterokedastisitas. Dari gambar di bawah dapat ditarik kesimpulan bahwa data responden dalam pengujian ini tidak bervariasi karena masih memiliki pola pikir yang sama dan respondennya merupakan wisatawan lokal.

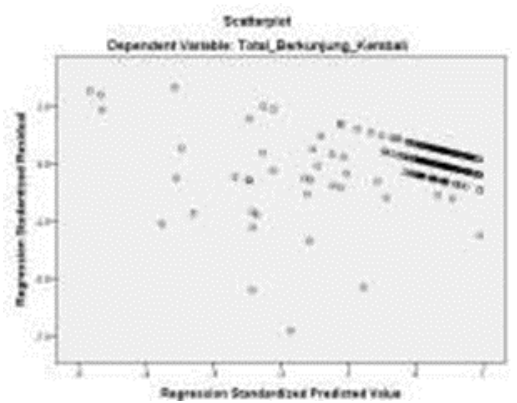

Gambar 2. Hasil Uji Heteroskedastisitas. 
Uji F

\begin{tabular}{lccccc}
\multicolumn{6}{c}{ Tabel 7. Hasil Uji F } \\
\hline & $\begin{array}{c}\text { Sum of } \\
\text { Squares }\end{array}$ & df & $\begin{array}{c}\text { Mean } \\
\text { Square }\end{array}$ & F & Sig. \\
\hline Regression & 320,938 & 4 & 80,235 & 34,913 & $.000 \mathrm{~b}$ \\
Residual & 636,580 & 277 & 2,298 & & \\
\hline Sund:
\end{tabular}

Sumber: Data Primer diolah (2020)

Hasil dari data diatas terdapat nilai sig < 0,05 maka ditarik kesimpulannya bahwa risiko fisik, risiko kepuasan, risiko waktu dan risiko keuangan berpengaruh secara signifikan terhadap berkunjung kembali. Sehingga model yang dapat digunakan untuk pengujian pada keinginan untuk mengunjungi kembali.

\section{Uji t}

Uji t dapat dilihat dari nilai Standardized Coefficients B pada varibel dalam tabel. Jika dihasilkan nilai positif (+) maka variabel dependen berpengaruh secara positif serta sebaliknya dengan syarat nilai sig $<0,05$.

Tabel 8. Hasil Uji t

\begin{tabular}{|c|c|c|c|c|}
\hline & $B$ & $\mathbf{t}$ & Sig. & Keterangan \\
\hline $\begin{array}{l}\text { Physical } \\
\text { Risk }\end{array}$ & $-0,086$ & $-1,287$ & 0,199 & $\begin{array}{c}\text { Tidak } \\
\text { Signifikan }\end{array}$ \\
\hline $\begin{array}{l}\text { Satisfaction } \\
\text { Risk }\end{array}$ & $-0,019$ & $-0,464$ & 0,643 & $\begin{array}{c}\text { Tidak } \\
\text { Signifikan }\end{array}$ \\
\hline Time Risk & $-0,177$ & $-2,241$ & 0,643 & Signifikan \\
\hline $\begin{array}{l}\text { Financial } \\
\text { Risk }\end{array}$ & $-0,176$ & $-3,391$ & 0,643 & Signifikan \\
\hline
\end{tabular}

Sumber: Data Primer diolah (2020)

Tabel ini menunjukkan bahwa time risk dan financial risk berpengaruh signifikan secara negatif terhadap revisit intention. Sedangkan Phyiscal Risk dan satisfaction risk tidak berpengaruh signifikan terhadap revisit intention. Teori kedua pada penelitian ini bahwa dihitung berdasarkan perbandingan nilai $\mathrm{t}$ hitung dan $\mathrm{t}$ tabel. Nilai $\mathrm{t}$ tabel didapatkan 1,97190 dikarenakan $\mathrm{df}=277$ dapat dilihat pada tabel ANOVA atau tabel uji $\mathrm{F}$ pada residual dan $\mathrm{t}=$ 0,025 (0,05 dibagi 2) ambil terbesarnya. Disimpulkan dari gambar diatas ini, nilai t hitung pada physical risk - 1,287 lebih besar dari 1,97190 maka tidak berpengaruh terhadap revisit intention, nilai t hitung pada satisfaction risk 0,464 maka tidak berpengaruh terhadap revisit intention, nilai t hitung pada time risk -2,241 maka lebih kecil dari - 1,97190 maka berpengaruh negatif terhadap revisit intention ${ }_{s}$ dan nilai $t$ hitung pada financial risk -3,391 lebih kecil dari -1,97190 maka memilki pengaruh negatif terhadap revisit intention.
Uji Koefisien Determinasi

Tabel 9. Hasil Uji Koefisien Determinasi (Adjusted R ${ }^{2}$ )

\begin{tabular}{ccc}
\hline Variabel & $\boldsymbol{R}$ Square & Adjusted $\boldsymbol{R}^{2}$ \\
\hline Berkunjung kembali & 0,335 & 0,326
\end{tabular}

Sumber: Data Primer diolah

Dari hasil diatas, nilai $\mathrm{R}$ sebesar 0,335 yang artinya bahwa variabel risiko fisik, risiko kepuasan, risiko waktu dan risiko keuangan mempunyai hubungan dengan berkunjung kembali sebesar 33,5\%. Dan juga bisa dilihat hasil yang diperoleh dari adjusted $R$ square yaitu 0,326 yang memiliki arti bahwa variabel dependen berkunjung kembali dapat dijelaskan ataupun dipengaruhi variabel independen, yaitu risiko fisik, risiko kepuasan, risiko waktu serta risiko keuangan sebesar $32,6 \%$ dan selebihnya dipengaruhi oleh faktor lainnya.

\section{KESIMPULAN DAN REKOMENDASI}

Tujuan dari penelitian ini adalah untuk mendapatkan hasil ataupun jawaban dari sebuah hipotesis pada pertanyaan penelitian yaitu apakah risiko fisik, risiko kepuasan, risiko waktu dan risiko keuangan memiliki pengaruh secara signifikan terhadap berkunjung kembali ke Kota Batam. Hasil dari penelitian ini dapat disimpulkan bahwa risiko fisik tidak berpengaruh secara signifikan terhadap keinginan untuk mengunjungi Kota Batam. Risiko kepuasan tidak berpengaruh secara signifikan terhadap mengunjungi Kota Batam. Risiko Waktu berpengaruh secara signifikan negatif terhadap keinginan untuk mengunjungi, berarti bahwa semakin tinggi risiko waktu maka semakin rendah keinginan untuk mengunjungi Kota Batam ataupun sebaliknya. Risiko Keuangan berpengaruh secara signifikan negatif terhadap keinginan untuk mengunjungi, berarti bahwa semakin tinggi risiko keuangan maka semakin rendah keinginan untuk mengunjungi Kota Batam ataupun sebaliknya.

\section{DAFTAR PUSTAKA}

Abdullah, D., Jayaraman, K., \& Kamal, S. B. M. (2016). A Conceptual Model of Interactive Hotel Website: The Role of Perceived Website Interactivity and Customer Perceived Value Toward Website Revisit Intention. Procedia Economics and Finance, 37(16), 170-175. https://doi.org/10.1016/s2212-

5671(16)30109-5 
Ali, F. (2015). Service quality as a determinant of customer satisfaction and resulting behavioural intentions: A SEM approach towards Malaysian resort hotels. Tourism, 63(1), 3752.

Artuğer, S. (2015). The Effect of Risk Perceptions on Tourists 'Revisit Intentions. 7(2).

Aziz, N. A., Ariffin, A. A. M., Omar, N. A., \& Evin, C. (2012). Examining the impact of visitors' emotions and perceived quality towards satisfaction and revisit intention to theme parks. Jurnal Pengurusan, 35(September), 97-109. https://doi.org/10.17576/pengurusa n-201235-09

Baker, D. A., \& Crompton, J. L. (2000). Quality, Satisfaction, and Behavior Intentions. Annals of Tourism Research.

Barnes, S. J., Mattsson, J., \& Sørensen,

F. (2016). Remembered experiences and revisit intentions: A longitudinal study of safari park visitors. Tourism Management, 57(July), 286294. https://doi.org/10.1016/j.tourman.2 016.06 .014

Çetinsöz, B. C., \& Ege, Z. (2013). Impacts of perceived risks on tourists' revisit intentions. Anatolia, 24(2), 173-187. https://doi.org/10.1080/13032917.2 012.743921

Chen, J. V., Htaik, S., Hiele, T. M. B., \& Chen, C. (2017). Investigating International Tourists' Intention to Revisit Myanmar Based on Need Gratification, Flow Experience and Perceived Risk. Journal of Quality Assurance in Hospitality and Tourism, 18(1), 25-44. https://doi.org/10.1080/1528008X. 2015.1133367

Chew, E. Y. T., \& Jahari, S. A. (2014).

Destination image as a mediator between perceived risks and revisit intention: A case of post-disaster Japan. Tourism Management, 40, 382-393.

https://doi.org/10.1016/j.tourman.2 013.07.008

Chew, T. Y. E., \& Jahari, A. S. (2014).
Destination image as a mediator between perceived risks and revisit: A case of postdisaster Japan. Tourism Management.

Goh, Y. N. (2015). Investigating revisit intentions for the boutique hotels of penang-A UNESCO world heritage site. Asian Social Science, 11(4), 126-134.

https://doi.org/10.5539/ass.v11n4p 126

Hair, J. F., Black, W. C., Babin, B. J., \& Anderson, R. E. (2010).

Multivariate Data Analysis (Seventh Ed). Pretince Hally, Upper Saddle River, New Jersey.

Han, H., Back, K. J., \& Barrett, B. (2009). Influencing factors on restaurant customers' revisit intention: The roles of emotions and switching barriers.

International Journal of Hospitality Management, $28(4)$,

563-572.

https://doi.org/10.1016/j.ijhm.2009

.03 .005

Hasan, M. K., Ismail, A. R., \& Islam, M.

F. (2017). Tourist risk perceptions and revisit intention: A critical review of literature. Cogent Business and Management, 4(1). https://doi.org/10.1080/23311975.2

017.1412874

Hashemi, S., Jusoh, J., Kiumarsi, S., \& Mohammadi, S. (2015). Influence factors of spa and wellness tourism on revisit intention: the mediating role of international tourist motivation and tourist satisfaction. International Journal of Research, 3(7), 1-11.

Herstanti, G., Suhud, U., \& Ferry WIBOWO, S. (2014). Three Modified Models to Predict Intention of Indonesian Tourists to Revisit Sydney. European Journal of Business and ManagementOnline), 6(25), 2222- 2839.

Huang, S., \& Hsu, C. H. C. (2009). Effects of travel motivation, past experience, perceived constraint, and attitude on revisit intention. Journal of Travel Research, 48(1), 29-44. https://doi.org/10.1177/004728750 8328793

Hung, W. L., Lee, Y. J., \& Huang, P. H. (2016). Creative experiences, memorability and revisit intention in creative tourism. Current Issues in 
$\begin{array}{lcc}\text { Tourism, } & 19(8), & 763-770 . \\ \text { https://doi.org/10.1080/13683500.2 } & \\ \text { 013.877422 } & \end{array}$

Hussein, A. S. (2016). How Event Awareness, Event Quality and Event Image Creates Visitor Revisit Intention?: A Lesson from Car free Day Event. Procedia Economics and Finance, 35(October 2015), 396-400. https://doi.org/10.1016/s2212-5671(16)000496

Indriantoro, N., \& Supomo, B. (2011). Metodologi Penelitian Bisnis Untuk Akuntansi Dan Manajemen (Edisi Pert). Yogyakarta: BPFE.

Julaimi, A. R., \& Talib, S. A. (2016). International tourists revisit intention: a case of the United Arab Emirates. Journal of Tourism, Hospitality \& Culinary Arts, 8(1), 35-42.

Jung, T., Ineson, E. M., Kim, M., \& Yap, M. H. T. (2015). Influence of festival attribute qualities on Slow Food tourists' experience, satisfaction level and revisit intention: The case of the Mold Food and Drink Festival. Journal of Vacation Marketing, 21(3), 277288.https://doi.org/10.1177/135676671 5571389

Kim, J. (Sunny), Song, H. J., Lee, C. K., \& Lee, J. Y. (2017). The impact of four CSR dimensions on a gaming company's image and customers' revisit intentions. International Journal of Hospitality Management, 61, 73-81. https://doi.org/10.1016/j.ijhm.2016.11.005

Lee, J. S., \& Kang, J. (2015). Fan Identification Effects of Sport Event Satisfaction on. Sport Marketing Quarterly, (January 2015).

Li, M., Cai, L. A., Lehto, X. Y., \& Huang, J. Z. (2010). A missing link in understanding revisit intention- the role of motivation and image. Journal of Travel and Tourism Marketing, 27(4), 335-348.

https://doi.org/10.1080/10548408.2 010.481559

Lin, C. H. (2013). Determinants of Revisit Intention to a Hot Springs Destination: Evidence from Taiwan. Asia Pacific Journal of Tourism Research, 18(3), 183-204. https://doi.org/10.1080/10941665.2 011.640698
Liu, C. H. S., \& Lee, T. (2016). Service quality and price perception of service: Influence on word-of- mouth and revisit intention. Journal of Air Transport Management, 52, 42-54. https://doi.org/10.1016/j.jairtraman .2015.12.007

Loi, L. T. I., So, A. S. I., Lo, I. S., \& Fong, L. H. N. (2017). Does the quality of tourist shuttles influence revisit intention through destination image and satisfaction? The case of Macao. Journal of Hospitality and Tourism Management, 32(September), 115-123. https://doi.org/10.1016/j.jhtm.2017.06.002

Marinkovic, V., Senic, V., Ivkov, D., Dimitrovski, D., \& Bjelic, M. (2014). The antecedents of satisfaction and revisit intentions for fullservice restaurants. Marketing Intelligence and Planning, 32(3), 311-327. https://doi.org/10.1108/MIP-01- 2013-0017

Pantouw, P., \& Pangemanan, S. S. (2014). The Effect of Destination Image and Tourist Satisfaction on Intention to Revisit in Lembeh Hill Resort. 2(3), 49-57.

Pattarakitham, A. (2015). The Influence of Customer Interaction, Variety, and Convenience on Customer Satisfaction and Revisit Intention: A Study of Shopping Mall in Bangkok. Journal of Economics, Business and Management, 3(11), 1072-1075. https://doi.org/10.7763/joebm.2015.v3.336

Pratminingsih, S. (2014). Roles of Motivation and Destination Image in Predicting Tourist Revisit Intention: A Case of Bandung - Indonesia. International Journal of Innovation, Management and Technology, 5(1). https://doi.org/10.7763/ijimt.2014. v5.479

Ranjbarian, B., \& Pool, J. K. (2015). The Impact of Perceived Quality and Value on Tourists' Satisfaction and Intention to Revisit Nowshahr City of Iran. Journal of Quality Assurance in Hospitality and Tourism, 16(1), 103-117. https://doi.org/10.1080/1528008X. 2015.966295

Santoso, S. (2012). Panduan Lengkap SPSS Versi 20 (P. E. M. Komputindo, ed.). Jakarta: PT Elex Media Komputindo. 
Shen, S. (2013). Intention to Revisit Traditional Folk Events: A Case Study of Qinhuai Lantern Festival, China. Tourism, 113(November 2012), 101-113. https://doi.org/10.1002/jtr

Siyoto, S., \& Sodik, M. A. (2015). Dasar Metodologi Penelitian (Ayub, ed.). Yogyakarta: Literasi Media Publishing.

Sobari, N., Usman, H., \& Wathani, M. Z. (2017). The Influence of Sharia Compliance and Marketing Mix on Satisfaction and Intention of Muslim Tourist to Revisit Sharia Hotel. 36(Icbmr), 645-656. https://doi.org/10.2991/icbmr-7.2017.58

Song, H. M., Kim, K. S., \& Yim, B. H. (2017). The mediating effect of place attachment on the relationship between golf tourism destination image and revisit intention. Asia Pacific Journal of Tourism Research, 22(11), $1182-$

1193.

https://doi.org/10.1080/10941665.2017.13777 40

Sönmez, S., \& Graefe, A. R. (n.d.). Determining Future Travel Behaviour form Past Travel Experience and Perceptions of Risk and Safety. Journal of Research.

Sugiyono. (2012). Metode Penelitian Kuantitatif Kualitatif dan $R \& D$. Bandung: Alfabeta.

Supranto. (2000). Metode Riset: Aplikasinya dalam Pemasaran. Jakarta: Rineka Cipta.

Thi Minh Pham, L., Nga Do, H., \& Minh Phung, T. (2016). The Effect of Brand Equity and Perceived Value on Customer Revisit Intention: A Study in Quick- Service Restaurants in Vietnam. Acta Oeconomica Pragensia, 2016(5), 14-30. https://doi.org/10.18267/j.aop.555

Tosun, C., Dedeoğlu, B. B., \& Fyall, A. (2015). Destination service quality, affective image and revisit intention: The moderating role of past experience. Journal of Destination Marketing and Management, 4(4), 222-234. https://doi.org/10.1016/j.jdmm.201 5.08.002

Zhou, Y. (2011). The Impact of Customer-Based Brand Equity on Revisit Intentions: An Empirical Study of Business and Leisure
Travelers at Five Shanghai Budget Hotels. 68-81. 